\title{
Self-Assembly of a Triazolylferrocenyl Dendrimer in Water Yields Non-Traditional Intrinsic Green Fluorescent Vesosomes for Nanotheranostic Applications ${ }^{\S}$
}

\author{
Gabriel Perli, ${ }^{\mathrm{a}}{ }^{\ddagger}$ Qi Wang, ${ }^{\mathrm{b}}{ }^{\star}+$ Carolyne B. Braga, ${ }^{\mathrm{a}}$ Diego L. Bertuzzi, ${ }^{\mathrm{a}}$ Liniquer A. Fontana, ${ }^{\mathrm{a}}$ \\ Marco C. P. Soares, ${ }^{c}$ Jaime Ruiz, ${ }^{\mathrm{b}}$ Jackson D. Megiatto Jr., ${ }^{\text {a Didier Astruc, }{ }^{\mathrm{b} *} \text { Catia Ornelas*a }}$ \\ aInstitute of Chemistry, Rua Josue de Castro, Cidade Universitaria Zeferino Vaz, University of Campinas, \\ 13083-970 Campinas, SP, Brazil. \\ ${ }^{\mathrm{b}}$ Groupe Nanosciences Moléculaires et Catalyse, Institut des Sciences Moléculaires, UMR CNRS № 5255 , \\ Université Bordeaux I, 351, Cours de la Libération, 33405 Talence Cedex, France \\ cLaboratory of Photonic Materials and Devices, Rua Mendeleyev 200, Cidade Universitaria Zeferino Vaz, \\ School of Mechanical Engineering, University of Campinas, 13083-860 Campinas, SP, Brazil \\ *Both authors contributed equally to this work \\ \$This communication is dedicated to Professor René Dabard at the occasion of his $90^{\text {th }}$ birthday
}

KEYWORDS. Dendrimer. Vesosome. Non-Traditional Intrinsic Fluorescence. Nanoparticle. Self-Assembly.

\section{Supporting Information}

Materials. For the development of this work, all chemicals were purchased from SigmaAldrich and used without further purifying. The TEM grids (Carbon Film-Copper, 400 mesh) were purchased from Electron Microscopy Sciences (EMS). Dimethyl sulfoxide (DMSO) was acquired as an anhydrous grade in a sealed flask. The triazolyferrocenyl dendrimer $\mathbf{1}$ were synthesized according to our previous report. ${ }^{1}$

Self-Assembly of Dendrimer in Water. The dendrimer $1(4 \mathrm{mg})$ was dissolved in $1.5 \mathrm{~mL}$ of DMSO. The solution was subjected to ultrasonication for $15 \mathrm{~min}$ to ensure complete homogenization. The total solubilization of Dendri-81-Fc 1 in DMSO resulted in an orange solution $(2.8 \mathrm{mg} / \mathrm{mL}, 69 \mu \mathrm{M}$ of $\mathbf{1}, 5.6 \mathrm{mM}$ of $\mathrm{Fc})$. From this dendrimer solution was taken $36 \mu \mathrm{L}$ and added to $1.964 \mathrm{~mL}$ of deionized water in a $15 \mathrm{~mL}$ Falcon tube. Then, the mixture was vortexed vigorously for 5 minutes and left to rest overnight at room temperature (Figure S3). The resulting solution (1.24 $\mu \mathrm{M}$ of $\mathbf{1})$ was colorless and clear, with no apparent formation of precipitates.

Self-Assembly of Dendrimer in Cell Culture Medium. Herein, a similar procedure to the one applied to synthesize the dendrimer vesosomes in water was employed. Particularly, in this case, $36 \mu \mathrm{L}$ of DMSO dendrimer solution was added to $1.964 \mathrm{~mL}$ of cell culture medium (DMEM) containing 10\% FBS. The mixture was vortexed vigorously for 5 minutes and left to 
rest overnight at room temperature. The resulting vesosome suspension was analyzed by DLS and employed at different concentration in cell viability assays.

Nuclear Magnetic Resonance (NMR) Spectroscopy. ${ }^{1} \mathrm{H}$ NMR spectra were recorded on a Bruker Avance III spectrometer operating at $600 \mathrm{MHz}$ for ${ }^{1} \mathrm{H}$. Spectra were obtained using solutions of $c a .10 \mathrm{mg}$ of dendrimer $1 \mathrm{in} 0.6 \mathrm{~mL}$ of deuterated solvents $\left(\mathrm{CDCl}_{3}\right.$ and DMSO- $\left.d_{6}\right)$. Chemical shifts are presented in ppm and referenced to solvent residual peaks $\left(\mathrm{CHCl}_{3}\right.$ in $\mathrm{CDCl}_{3}$ at $7.24 \mathrm{ppm}$ or DMSO in DMSO- $d_{6}$ at $2.50 \mathrm{ppm}$ ).

Ultraviolet-visible (UV-vis) Absorption Spectroscopy. UV-vis absorption spectra were recorded on an Agilent HP 8453 spectrophotometer at $25^{\circ} \mathrm{C}$ using a $1 \mathrm{~cm}$ quartz cuvette. Stock solutions were prepared at a concentration of $0.5 \mathrm{mM}$ of dendrimer 1 in chloroform and dimethyl sulfoxide. Solutions were prepared just prior to use from dilutions of the stock solutions.

Dynamic Light Scattering (DLS). Size distribution and polydispersity index (PDI) of dendrimer 1 assemblies in nanopure water $(1.24 \mu \mathrm{M}$ of $\mathbf{1})$ were determined using dynamic light scattering (DLS). Measurements were carried out at $25^{\circ} \mathrm{C}$ using a disposable DTS 1070 cuvette on a Zetasizer Nano-ZS ZEN3600 instrument (Malvern Instruments Ltd.) equipped with a 4 $\mathrm{mW} \mathrm{He}-\mathrm{Ne}$ laser with wavelength of $632.8 \mathrm{~nm}$, and an autocorrelator with a $173^{\circ}$ detection angle of scattered light.

Nanoparticle Tracking Analysis (NTA). Size distribution of nanoassembly formed by dendrimer 1 in aqueous medium was determined by NTA using a Malvern Nanosight LM-10 instrument. The sample was prepared by diluting 10,000 times the dendrimer nanoassembly in ultrapure water and filtered through a $0.45 \mu \mathrm{m}$ syringe filter prior use. Particle sizes are given as the average of three measurements \pm standard deviation (SD).

Scanning Electron Microscopy (SEM). The surface morphology of dendrimer vesosomes was assessed using a Quanta 250 field emission scanning electron microscope (FESEM) (FEI Ltd.) operating at an accelerating voltage of $15 \mathrm{kV}$. The samples were prepared by dropping $15 \mu \mathrm{L}$ of a vesosome suspension (1.24 $\mu \mathrm{M}$ of $\mathbf{1}$ in deionized water) onto a polished silicon wafer. Samples were allowed to dry overnight under nitrogen atmosphere, and sputtercoated with a layer of iridium in a Bal-Tec MD 020 instrument (Balzers).

Energy-Filtered Transmission Electron Microscopy. The surface morphology and size distribution of dendrimer vesosomes were also assessed using a transmission electron microscope model Libra 120 (Zeiss) operated at $80 \mathrm{kV}$. The samples were prepared by dropping $5 \mu \mathrm{L}$ of a vesosome suspension (1.24 $\mu \mathrm{M}$ of 1 in deionized water) onto a TEM grid (Carbon Film-Copper, 400 mesh, EMS). Samples were allowed to dry in a desiccator at room temperature. The images were acquired by using the Olympus imaging system equipped with a Cantega G2 camera 2048 x 2048 pixels, 14 bits). All the images were processed in the iTEM software. 
Energy-Dispersive X-ray Spectroscopy (EDS). The elemental analysis was carried out using a Quanta 250 field emission scanning electron microscope (FESEM) (FEI Ltd.) equipped with an X-Max SDD - $50 \mathrm{~mm}^{2}$ detector (Oxford Instruments Aztec). To achieve ideal measurement conditions for the elements with lower atomic numbers, such as $\mathrm{C}, \mathrm{N}$ and $\mathrm{O}$, the equipment was operated at an accelerating voltage of $10 \mathrm{kV}$, and a beam current of $1.0 \mathrm{nA}$. To accumulate a statistical number of counts in the X-ray spectra, each point was irradiated by $60 \mathrm{~s}$. For the elemental mapping, $10 \mathrm{~min}$ was used for each area segment of $0.05 \mu \mathrm{m} \times 0.05 \mu \mathrm{m}$. The samples were prepared by dropping $5 \mu \mathrm{L}$ of a vesosome suspension (1.24 $\mu \mathrm{M}$ of $\mathbf{1}$ in deionized water) onto a polished silicon wafer. Samples were left to dry overnight in air atmosphere, and sputtercoated with a layer of iridium in a Bal-Tec MD 020 instrument (Balzers). The attribution of the elements was automatically carried out by the equipment software based on the internal database.

Confocal Laser Scanning Microscopy (CLSM). The fluorescence of dendrimer assemblies was assessed by confocal laser scanning microscopy (CLSM). The samples were prepared by dropping $15 \mu \mathrm{L}$ of a vesosome suspension $(1.24 \mu \mathrm{M}$ of 1 in deionized water) onto a glass coverslip with thickness of $0.13 \mathrm{~mm}$. The analyses were carried out on a Zeiss LSM 880 microscope equipped with the transmitted light (T-PMT) and AiryScan detectors. The images were acquired using a laser diode (5\% of power) for excitation at $405 \mathrm{~nm}$, and a C PlanApochromat 63x/1.4 Oil DIC (WD:0.14 mm) objective. The acquisition setup was $2.5 \mu \mathrm{s}$ per time point, gain at 700 , and maximum pinhole aperture. The emission spectrum was measured using a three-channel photomultiplier detector allowing fluorescence detection in the range of 400 to $700 \mathrm{~nm}$. The files were saved in .czi format and processed in the Fiji ImageJ software.

Cell Culture. Human breast cancer cells (MCF-7) were cultured in RPMI-1640 containing $10 \%$ FBS and $1 \%$ penicillin-streptomycin at $37{ }^{\circ} \mathrm{C}$ under a $5 \% \mathrm{CO}_{2}$ humidified atmosphere.

In Vitro Cytotoxicity Assay. The MCF-7 cells were seeded in a 96-well plate (at a density of 7,500 cells per well) containing $200 \mu \mathrm{L}$ of complete cell culture medium and incubated overnight at $37{ }^{\circ} \mathrm{C}$ in a humidified atmosphere with $5 \% \mathrm{CO}_{2}$. The medium was then replaced for fresh medium $(200 \mu \mathrm{L})$ containing the dendritic vesosomes at different concentrations (0.10-150.0 $\mu \mathrm{M}$ of ferrocenyl groups). After treatment of cells with the vesossomes for 24 hours and 48 hours, the culture solution was aspirated, the cells were washed twice with PBS $1 \mathrm{X}$, and the cell viability was evaluated using the Cell Counting Kit-8 (CCK-8) according to the manufacturer's instructions. The absorbance of the solution in each well at $450 \mathrm{~nm}$ was measured using a microplate reader (FlashScan 530 Analitic Jena). All samples were tested in triplicate. Cells without treatment served as control and the corresponding viability was set as $100 \%$.

Cell imaging with Cytation ${ }^{\mathrm{TM}}$ 5. Cells were observed and imaged using a Cytation ${ }^{\mathrm{TM}} 5$ Cell Imaging Multi-Mode Reader (BioTek Instruments, Inc., Winooski, VT) configured with a GFP light cube. The microscope uses a combination of LED light sources in conjunction with band pass filters to provide the appropriate wavelength of light. The GFP light cube uses a $469 \mathrm{~nm}$ excitation filter and a $525 \mathrm{~nm}$ emission filter. Installed objectives include 4x, 10x, and 20x 
magnifications. Imaging was carried out in living cells using a 96-well plate, at $37{ }^{\circ} \mathrm{C}$ in a humidified atmosphere with $5 \% \mathrm{CO}_{2}$. After $24 \mathrm{~h}$ of incubation with dendritic vesosomes (at 10 $\mu \mathrm{M}$ of $\mathrm{Fc})$, cells were irradiated with GFP laser $(100 \mathrm{~mW})$ and images were captured.

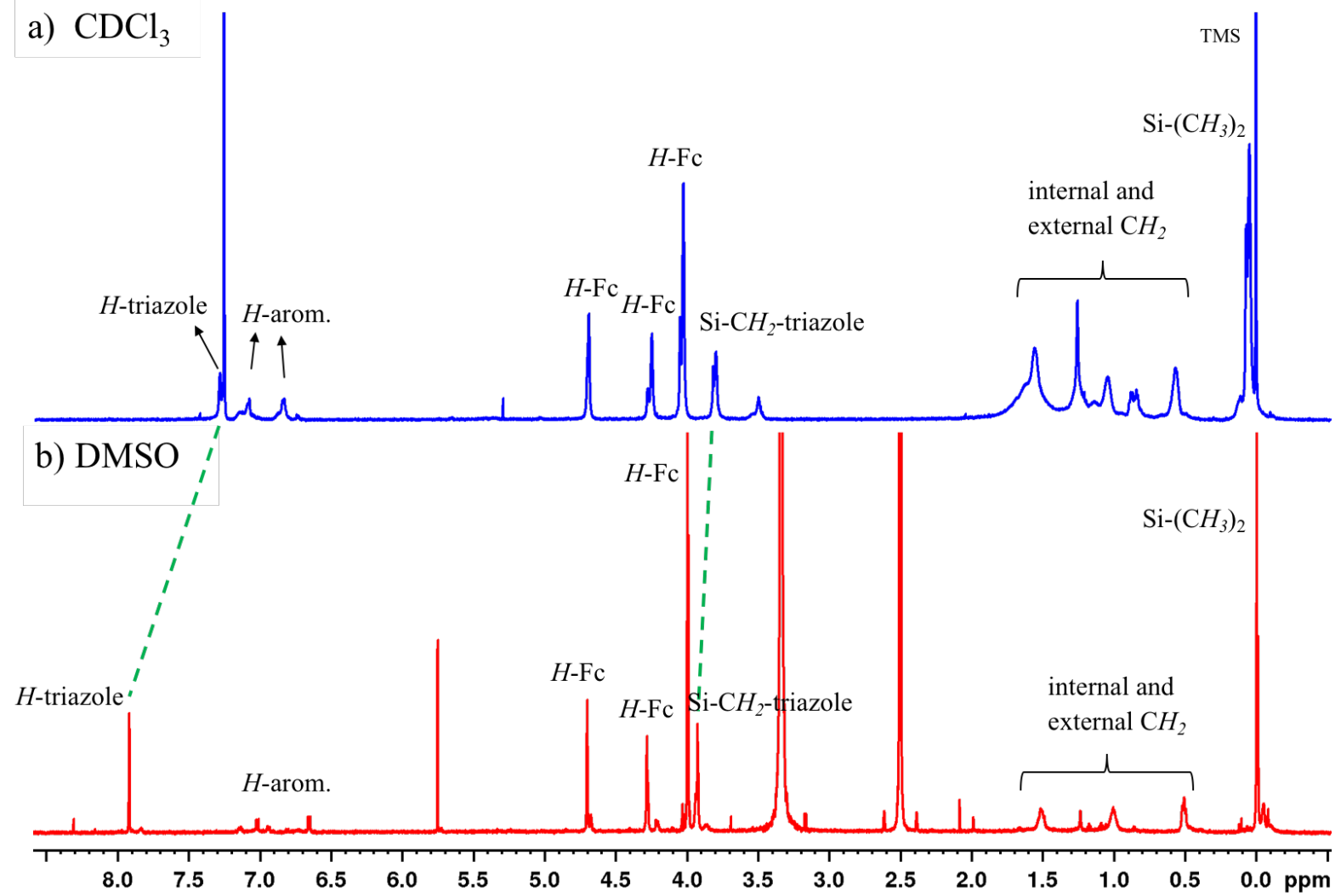

Figure S1. Comparison of the ${ }^{1} \mathrm{H}$ NMR spectra of dendrimer Dendri-81-Fc 1 in (a) $\mathrm{CDCl}_{3}$ and (b) DMSO- $d_{6}$, at $600 \mathrm{MHz}$.

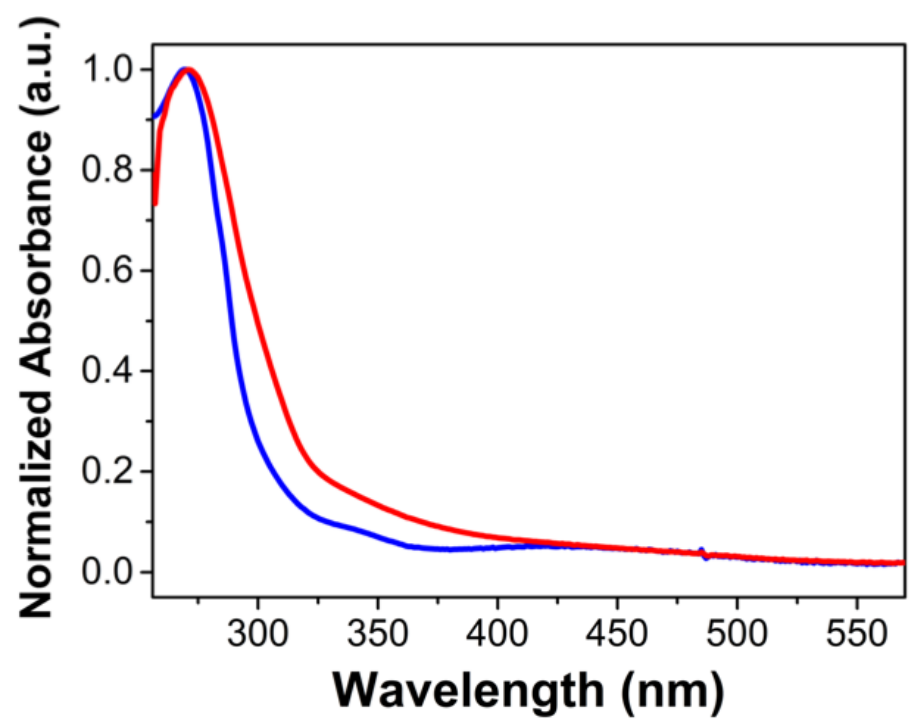

Figure S2. Absorption spectra of dendrimer 1 normalized to the triazole band in chloroform (blue) and DMSO (red). 


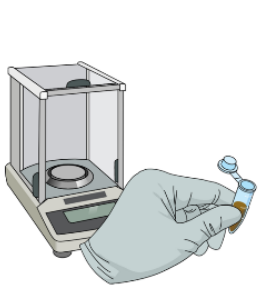

1
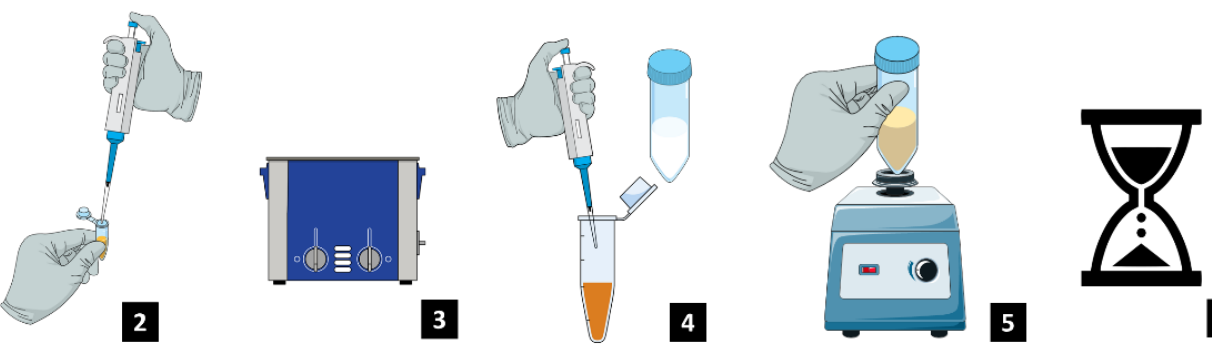

5

6

Figure S3. Schematic representation of the procedure used to induce the self-assembly of Dendri-81-Fc 1 in aqueous medium: (1) $4 \mathrm{mg}$ of the ferrocenyl-dendrimer was weighed; and (2) dissolved in $1.5 \mathrm{~mL}$ of DMSO; (3) sonicated until complete solubilization. Then, (4) $36 \mu \mathrm{L}$ of the dendrimer solution was dispersed in $1.964 \mathrm{~mL}$ of deionized water; (5) the mixture was vortexed for $5 \mathrm{~min}$; (6) the vesosome suspension was left to rest overnight at room temperature sheltered from light.

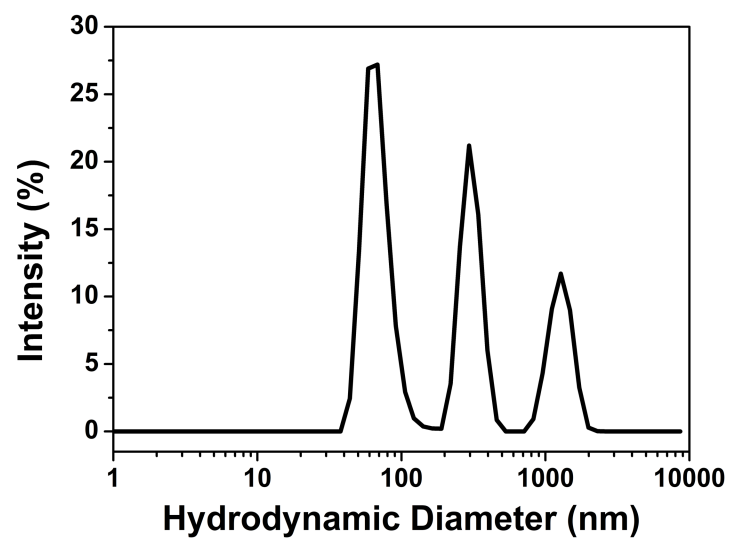

Figure S4. Hydrodynamic diameter of the self-assemblies formed by 1 in water, 15 min after adding the DMSO dendrimer solution into water, obtained by DLS.

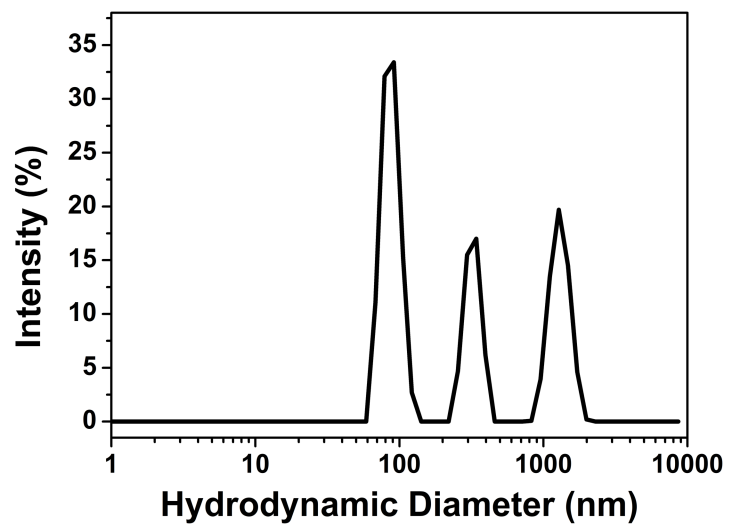

Figure S5. Hydrodynamic diameter of the self-assemblies formed by $\mathbf{1}$ in water, 2 hours after adding the DMSO dendrimer solution into water, obtained by DLS. 


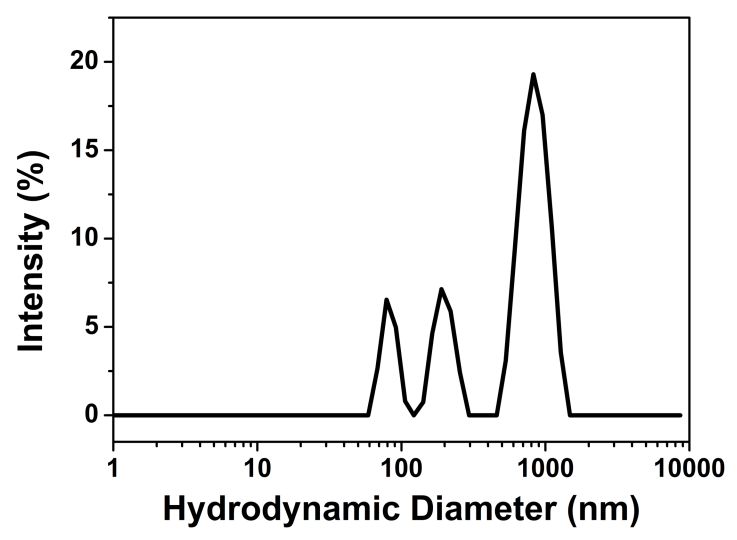

Figure S6. Hydrodynamic diameter of the self-assemblies formed by $\mathbf{1}$ in water, 4 hours after adding the DMSO dendrimer solution into water, obtained by DLS.

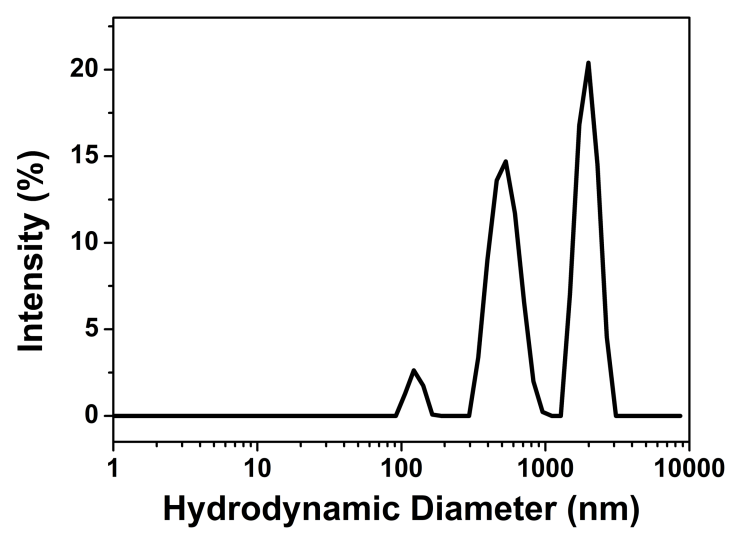

Figure S7. Hydrodynamic diameter of the self-assemblies formed by $\mathbf{1}$ in water, 8 hours after adding the DMSO dendrimer solution into water, obtained by DLS.

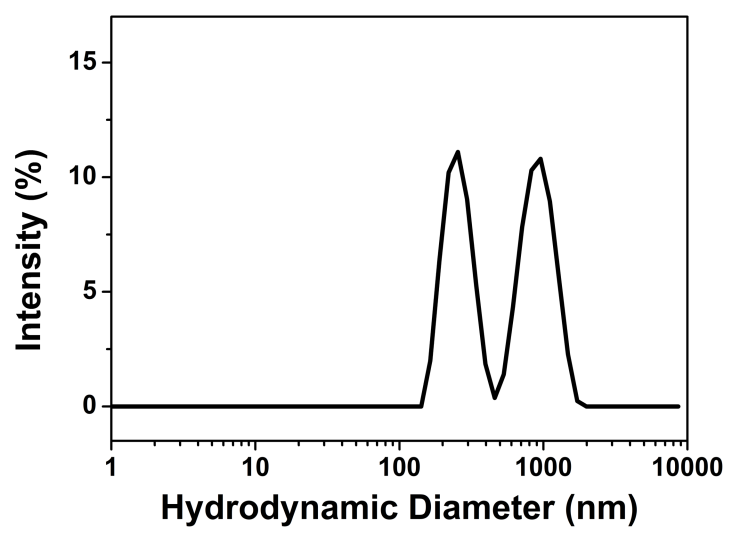

Figure S8. Hydrodynamic diameter of the self-assemblies formed by 1 in water, 10 hours after adding the DMSO dendrimer solution into water, obtained by DLS. 

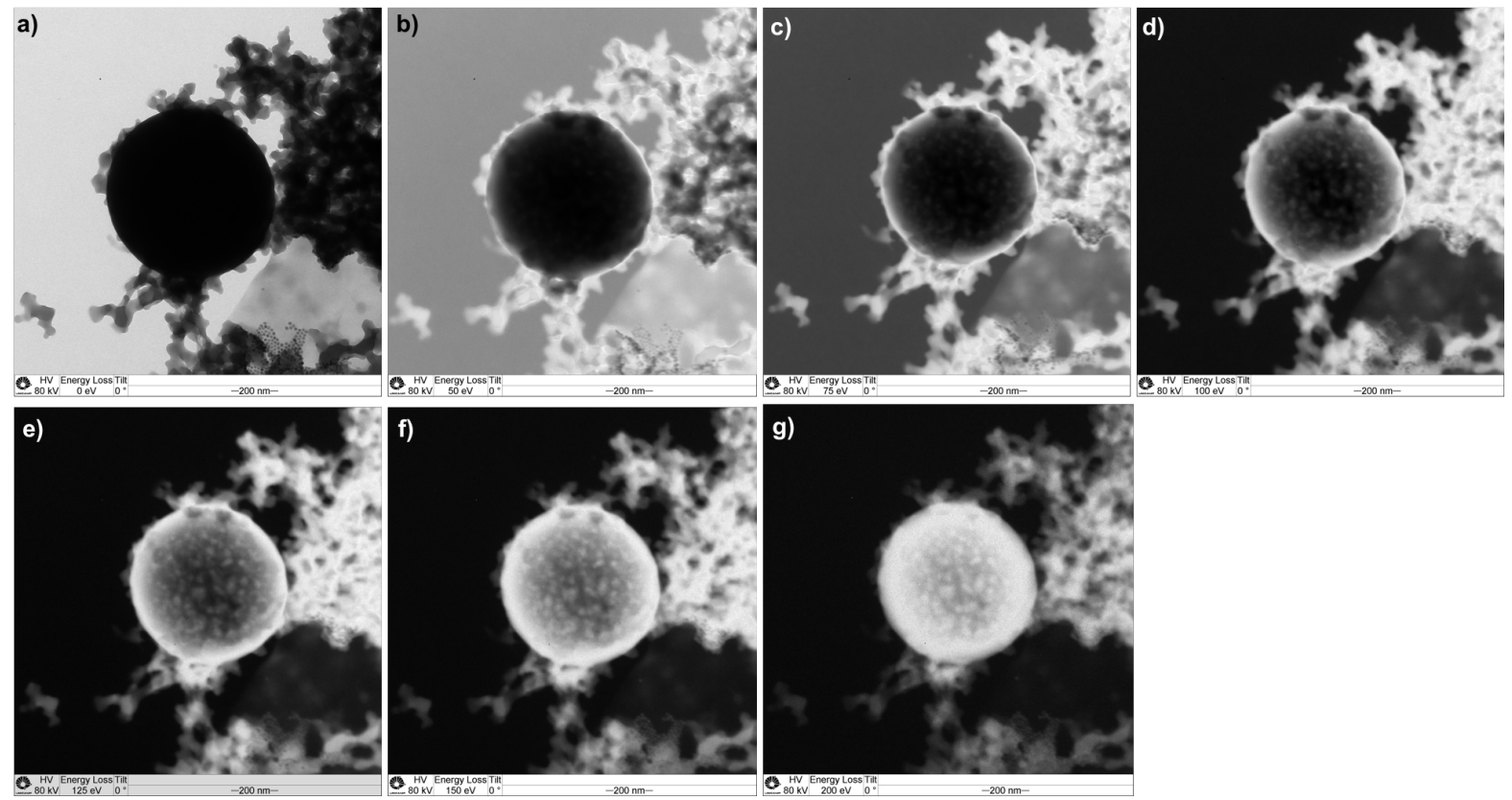

Figure S9. Energy-Filtered Transmission Electron Microscopy images (0-200 eV energy loss) of the three structures formed by the dendrimer 1 (dendrimer 1, nanoparticles and vesosome): (a) $0 \mathrm{eV}$ energy loss, (b) $50 \mathrm{eV}$ energy loss, (c) $75 \mathrm{eV}$ energy loss, (d) $100 \mathrm{eV}$ energy loss, (e) $125 \mathrm{eV}$ energy loss, (f) $150 \mathrm{eV}$ energy loss, (g) $200 \mathrm{eV}$ energy loss. 
a)
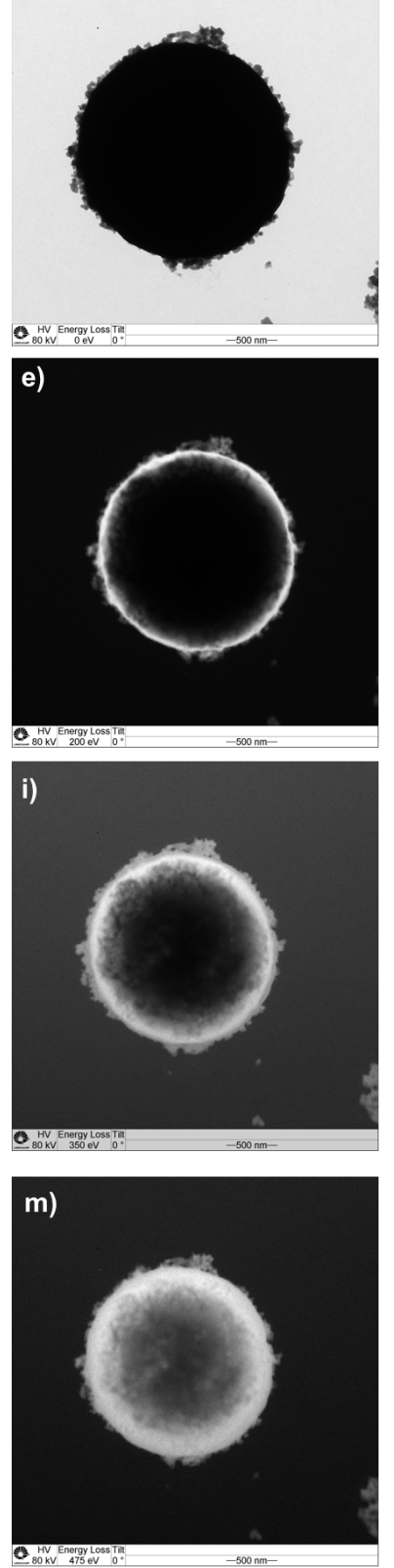

b)
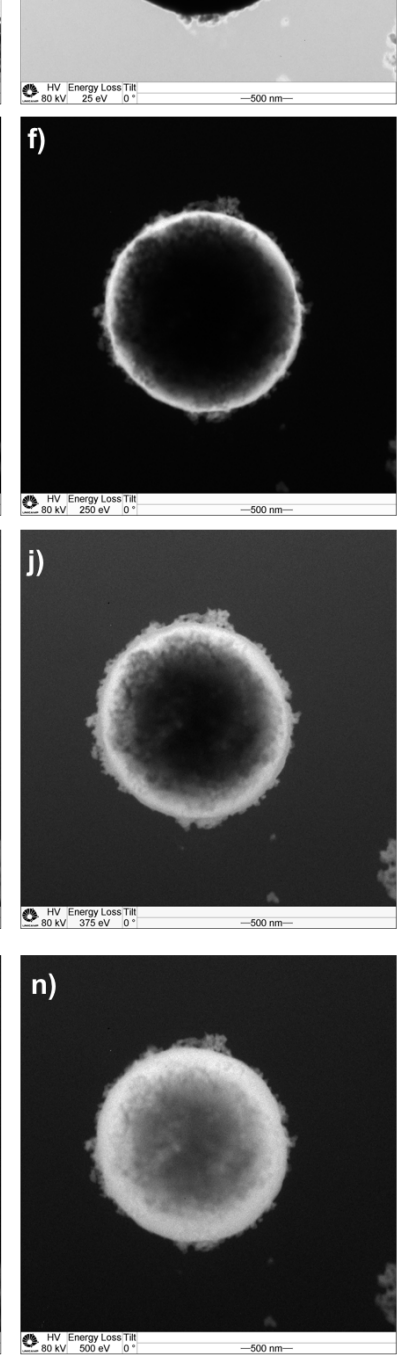
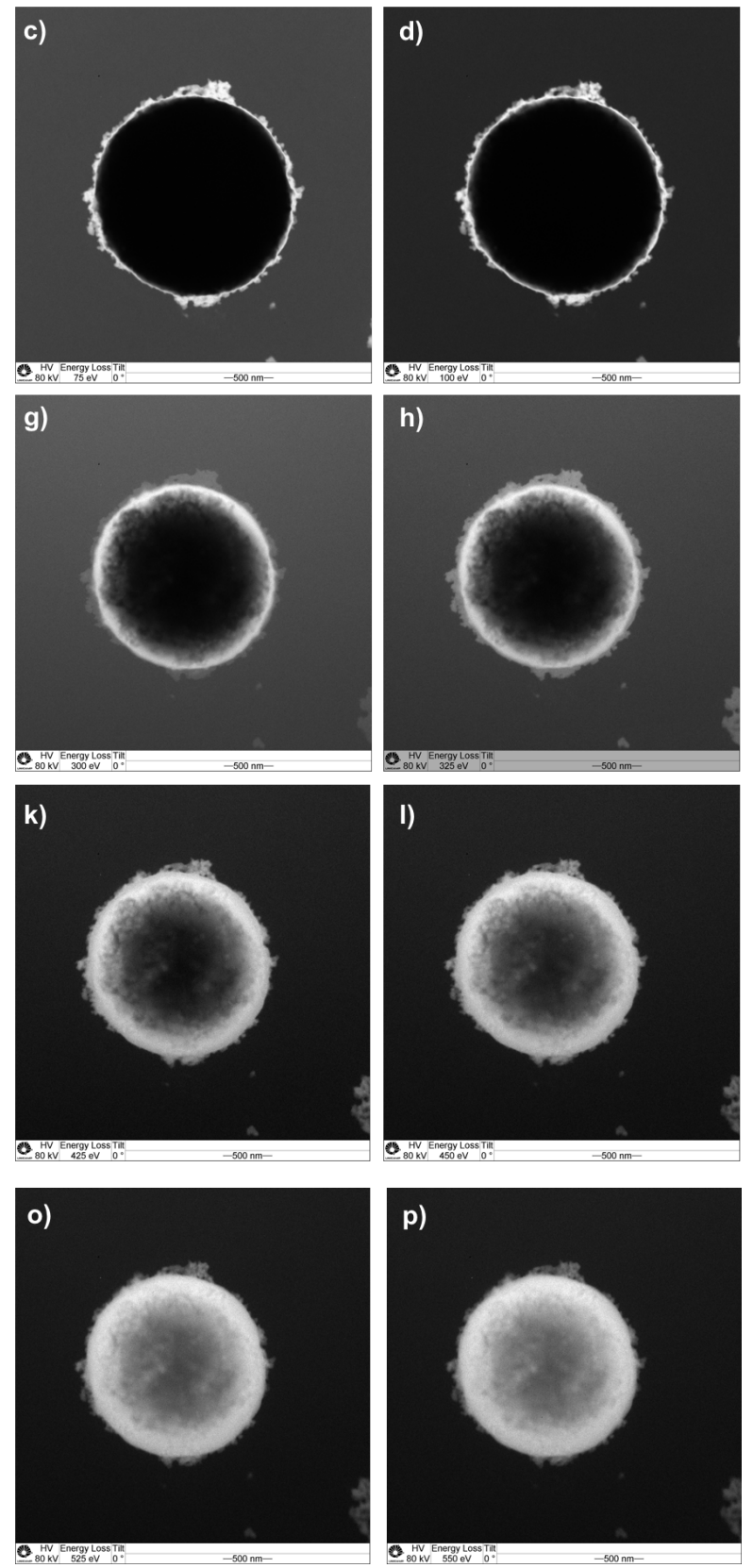

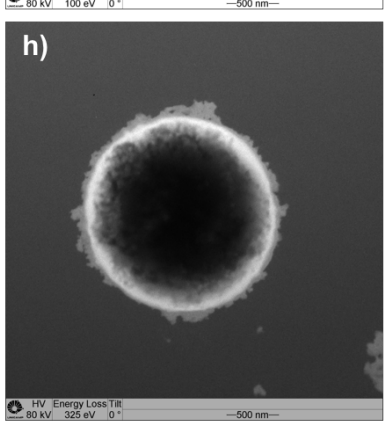

I)
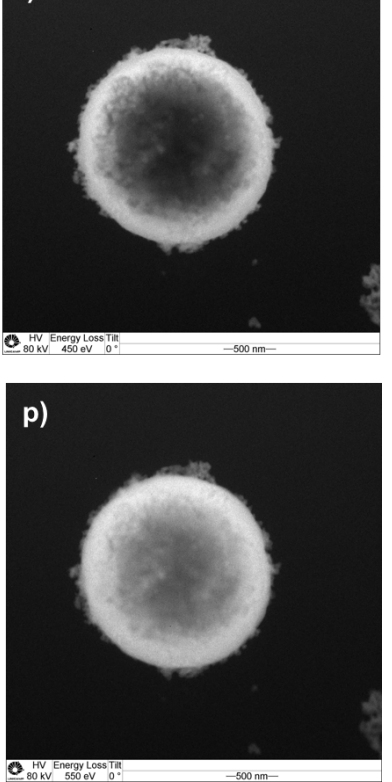

Figure S10. Energy-Filtered Transmission Electron Microscopy images (0-550 eV energy loss) of the three structures formed by the dendrimer 1 (dendrimer $\mathbf{1}$, nanoparticles and vesosome): (a) $0 \mathrm{eV}$ energy loss, (b) $25 \mathrm{eV}$ energy loss, (c) $75 \mathrm{eV}$ energy loss, (d) $100 \mathrm{eV}$ energy loss, (e) $200 \mathrm{eV}$ energy loss, (f) $250 \mathrm{eV}$ energy loss, (g) $300 \mathrm{eV}$ energy loss, (h) $325 \mathrm{eV}$ energy loss, (i) $350 \mathrm{eV}$ energy loss, (j) $375 \mathrm{eV}$ energy loss, (k) $425 \mathrm{eV}$ energy loss, (l) $450 \mathrm{eV}$ energy loss, (m) $475 \mathrm{eV}$ energy loss, (n) $500 \mathrm{eV}$ energy loss, (o) $525 \mathrm{eV}$ energy loss, (p) $550 \mathrm{eV}$ energy loss. 


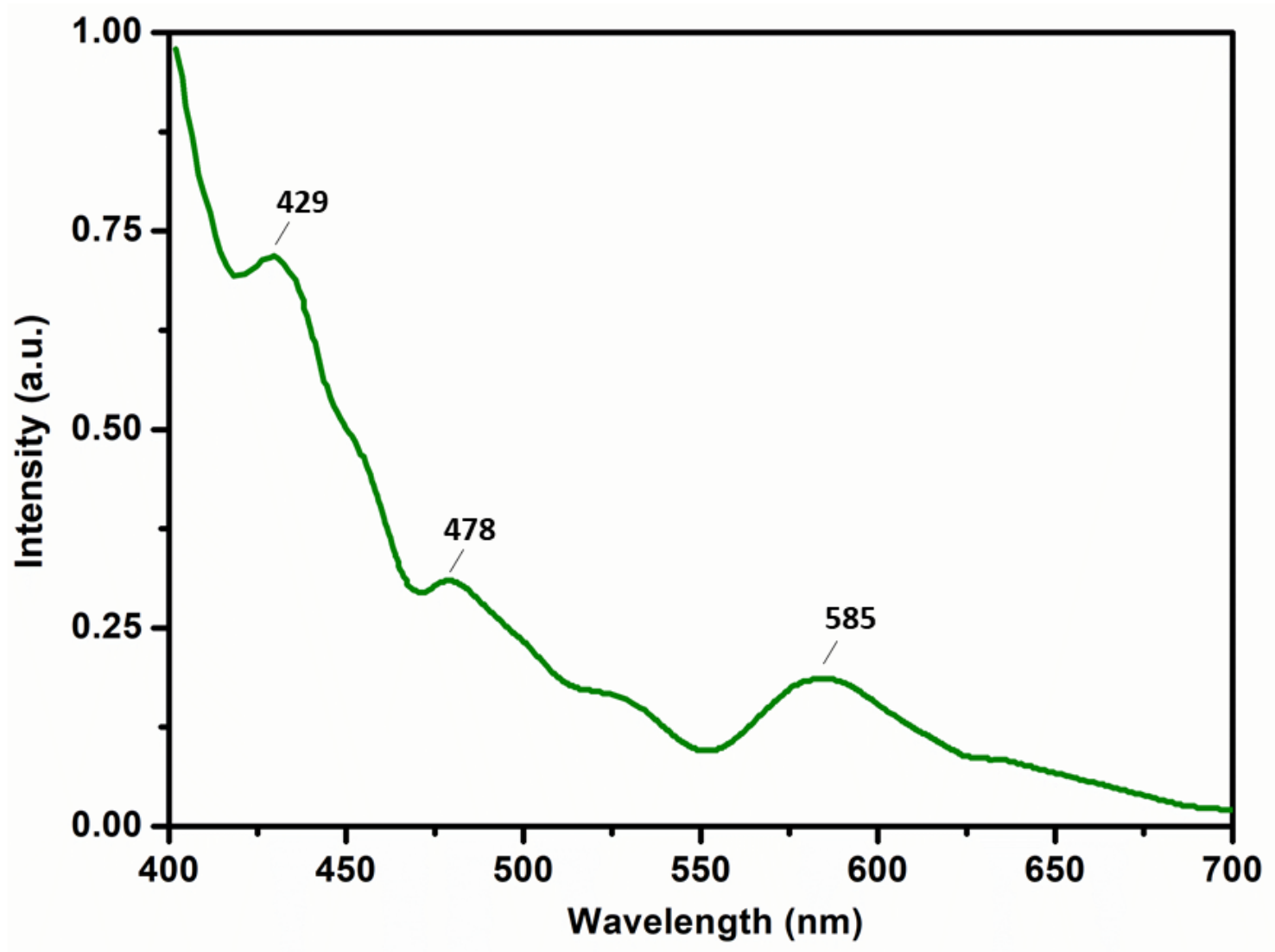

Figure S11. Fluorescence emission spectrum excited at $405 \mathrm{~nm}$ for the vesosome suspension at concentration of $1.24 \mu \mathrm{M}$ of 1 in deionized water, obtained by confocal microscopy. 

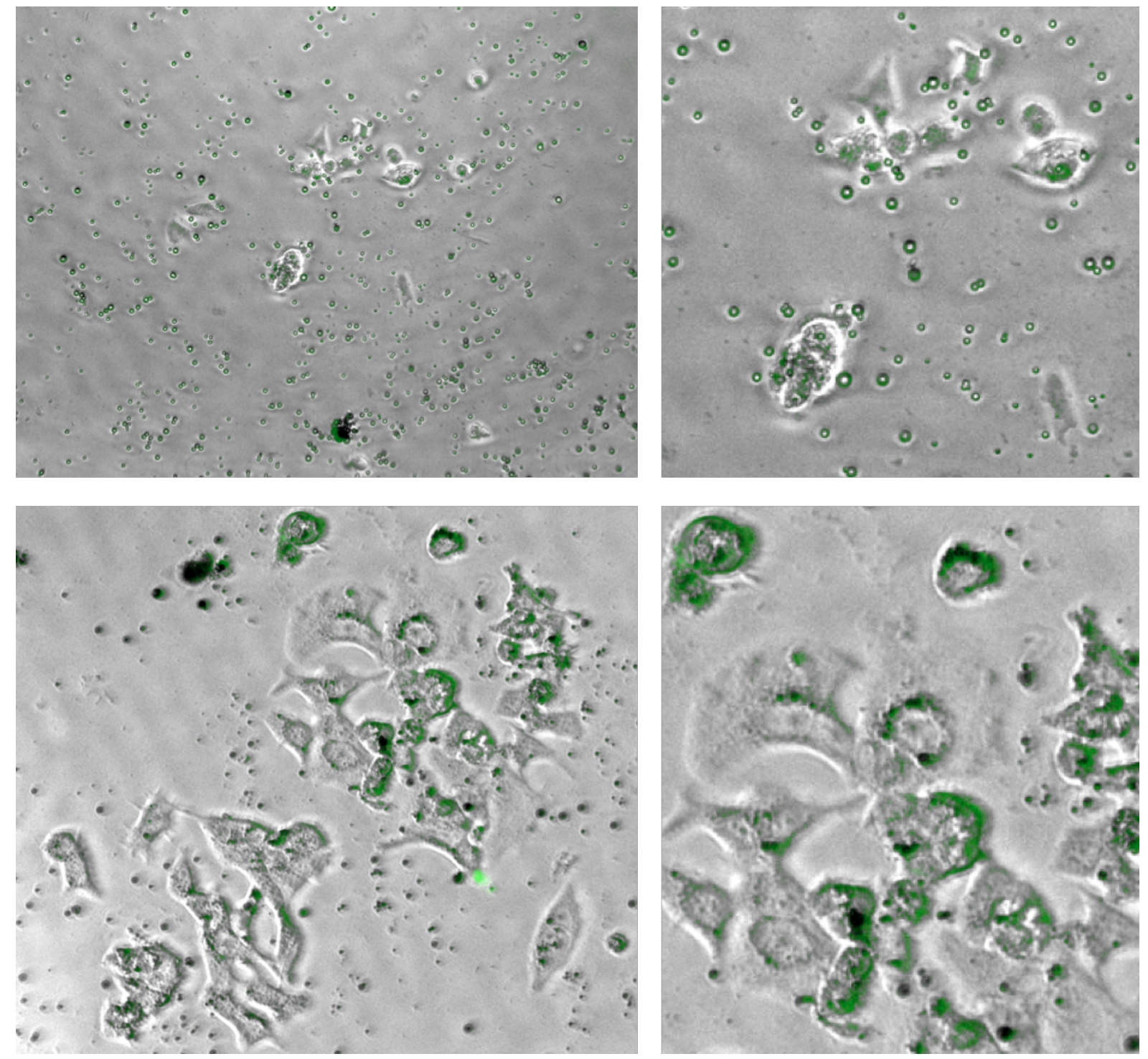

Figure S12. Merged images of bright field and fluorescent images captured with GFP filter (excitation wavelength: $469 \mathrm{~nm}$; emission detector wavelength: $525 \mathrm{~nm}$ ) in a Cytation 5 reader of MCF-7 cells incubated for $24 \mathrm{~h}$ with vesosomes assembled from dendrimer 1 . Top left: region 1; top right: zoom in on region 1; bottom left: region 2; bottom left: zoom in on region 2. 


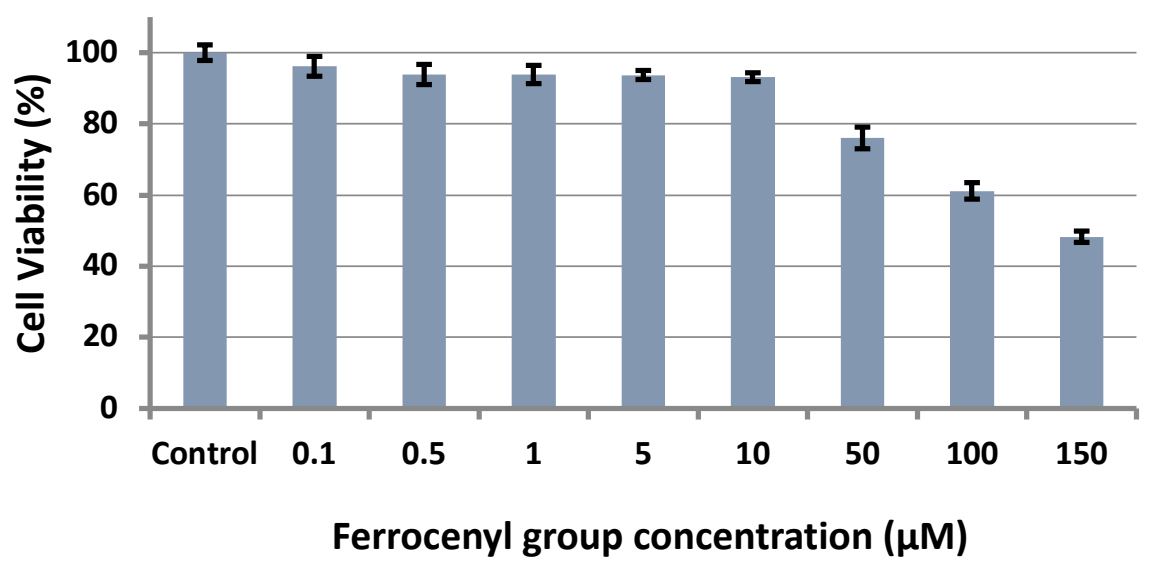

Figure S13. Cell viability of MCF-7 cells incubated with vesosomes formed by the trizolylferrocenyl dendrimer $\mathbf{1}$ at varying concentrations for $24 \mathrm{~h}$ (concentration was calculated per ferrocenyl group). Data are expressed as the mean $\pm \operatorname{SD}(n=3)$.

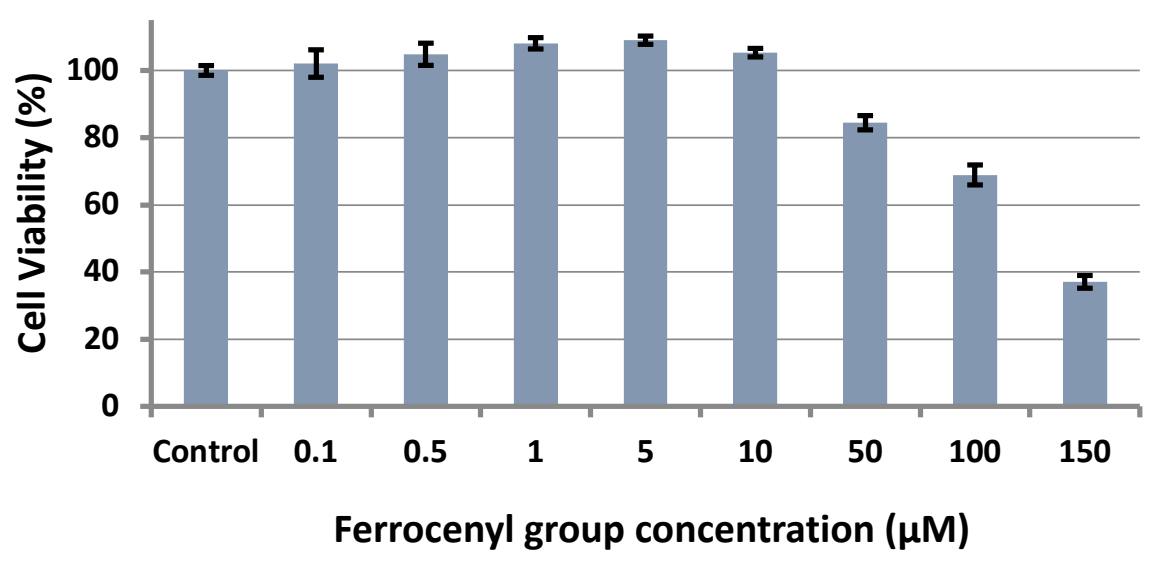

Figure S14. Cell viability of MCF-7 cells incubated with vesosomes formed by the trizolylferrocenyl dendrimer 1 at varying concentrations for $48 \mathrm{~h}$ (concentration was calculated per ferrocenyl group). Data are expressed as the mean $\pm \operatorname{SD}(n=3)$.

1. Ornelas, C.; Aranzaes, J. R.; Salmon, L.; Astruc, D., "Click" dendrimers: Synthesis, redox sensing of $\mathrm{Pd}(\mathrm{OAc})(2)$, and remarkable catalytic hydrogenation activity of precise $\mathrm{Pd}$ nanoparticles stabilized by 1,2,3-triazole-containing dendrimers. Chemistry-a European Journal 2008, 14 (1), 50-64. 